\title{
DESIGUALDADES EDUCACIONAIS DA POPULAÇ̃̃O NEGRA DO BRASIL: UM CONTEXTO SÓCIO-HISTÓRICO
}

\author{
EDUCATIONAL INEQUALITIES AMONG THE BLACK POPULATION IN BRAZIL: A \\ SOCIOHISTORICAL CONTEXT \\ DESIGUALDADES EDUCATIVAS DE LA POBLACIÓN NEGRA DE BRASIL: UN CONTEXTO
SOCIO-HISTÓRICO
}

Marcos Antonio Batista da Silva*

\begin{abstract}
RESUMO
O artigo é parte de uma discussão teórica derivada de tese de doutorado desenvolvida num Programa de Psicologia Social, que teve como objetivo investigar as desigualdades educacionais da população negra no Brasil, entre outros. $\mathrm{O}$ estudo chama a atenção para as desigualdades educacionais dessa população, no que se refere à falta de acesso à escola e à educação formal. Para tal, realizamos uma revisão de literatura de autores contemporâneos, sobre o tema das relações étnico-raciais, bem como de aportes teóricos sobre desigualdades educacionais e legislação no País. No campo metodológico, utilizamos a hermenêutica de profundidade (HP), proposta por Thompson (2011), além da análise de conteúdo ancorada em Bardin (2011). Concluiuse que a desigualdade educacional da população negra no Brasil passou por transformações em contextos sócio-históricos, de uma legislação a outra. As ações governamentais com vistas à superação da desigualdade racial, de maneira geral, pairam sob o binômio inclusão/exclusão.
\end{abstract}

Palavras-chave: Negros. Relações étnico-raciais. Desigualdades educacionais.

\begin{abstract}
This article is part of a theoretical discussion triggered off by a research thesis within a PhD Social Psychology Program. The aim of the research was, among others, to investigate the educational inequalities among Brazilian black population. The study highlights the educational unevenness amidst this population, as imparities regarding access to schooling and lack of formal learning. Contemporary literature on ethnic-racial relations and theoretical contributions to educational inequalities were reviewed, in addition to Brazilian legislation. Regarding methodology, Depth Hermeneutics, as proposed by Thompson (2011), was employed, as well as the content
\end{abstract}

\footnotetext{
Texto recebido em 23 de maio de 2017 e aprovado para publicação em 4 de julho de 2018.

Investigador em pós-doutoramento no Centro de Estudos Sociais da Universidade de Coimbra (CES), Coimbra, Portugal, onde integra o Projeto "Politics - The politics of anti-racism in Europe and Latin America: knowledge production, decision-making and collective struggles". Financiamento: European Research Council (Projeto: 725402 - Politics - ERC-2016-COG); doutor em Psicologia Social pela Pontifícia Universidade Católica de São Paulo (PUC-SP). Endereço: Rua da Sofia, 136-138 - 3000 389, Coimbra, Portugal. E-mail: marcos.psico@yahoo.com.br.
} 
analysis based upon Bardin (2011). In conclusion, it would appear that educational inequality among Brazilian black population was subjected to transformations during different sociohistorical contexts from one legislation to another. Official actions taken to eliminate racial inequality, in general, are hovered by an inclusion/exclusion binomial.

Keywords: Black population. Ethnic-racial relations. Inequalities.

\section{RESUMEN}

Este artículo forma parte de una discusión teórica derivada de una tesis doctoral desarrollada en un Programa de Psicología Social que tuvo como objetivo investigar las desigualdades educativas de la población negra en Brasil, entre otros. El estudio llama la atención sobre las desigualdades educativas de esta población, en lo que se refiere a la falta de acceso a la escuela y a la educación formal. Para ello, realizamos una revisión de literatura de autores contemporáneos sobre el tema de las relaciones étnico-raciales, así como de aportes teóricos sobre desigualdades educativas y legislación en el país. En el campo metodológico, utilizamos la hermenéutica de profundidad (HP), propuesta por Thompson (2011), además del análisis de contenido anclado en Bardin (2011). Se concluyó que la desigualdad educativa de la población negra en Brasil pasó por transformaciones en contextos sociohistóricos de una legislación a otra. Las acciones gubernamentales dirigidas a la superación de la desigualdad racial, de manera general, se encuentran bajo el binomio inclusión / exclusión.

Palabras clave: Negros. Relaciones étnico-raciales. Desigualdades educativas.

\section{INTRODUÇÃO}

$\mathrm{E}$ ste artigo é parte de uma discussão teórica derivada de tese de doutorado desenvolvida em um Programa de Psicologia Social, isto é, parte-se de um recorte da pesquisa da tese Discursos étnico-raciais proferidos por pesquisadores/ as negros/as na pós-graduação: acesso, permanência, apoios e barreiras (Silva, 2016). A investigação forneceu elementos para discussão acerca das desigualdades étnico-raciais no sistema educacional brasileiro e as narrativas e estratégias de estudantes negros utilizadas para o ingresso, permanência e titulação na pósgraduação (mestrado) em São Paulo.

Entende-se que uma particularidade da sociedade brasileira é que a formação e a prática em pesquisa ocorrem, quase que exclusivamente, no âmbito da pós-graduação. O censo de 2010 é o primeiro em que o número de pessoas autodeclaradas negras supera a população branca. Esse é um fato importante, 
porque reflete no ingresso de negros à pós-graduação e sugere uma mobilidade educacional, atualmente provocada em parte pelas políticas de ação afirmativa com recorte racial na graduação. É como se houvesse uma "demanda reprimida" de acesso dos negros à educação superior, devido às desigualdades sociais e ao racismo estrutural no País.

É uma tarefa difícil, contudo, tentar delimitar uma conceituação precisa, com aceitação geral em um campo específico de estudos sobre as relações étnico-raciais no Brasil, no que tange às desigualdades educacionais da população negra. Isso porque, como toda expressão simbólica, a desigualdade educacional foi criada e está sendo transformada nos contextos sócio-históricos, de uma legislação a outra, devido a lutas constantes dos movimentos sociais negro (Movimento Negro) de introduzir esta pauta no contexto social e político na sociedade brasileira (Gomes, \& Rodrigues, 2018). Ao revisitarmos essa literatura, no que se refere à desigualdade educacional da população negra no País, apreende-se que tal desigualdade vem de longa data. Formalmente, a Constituição de 1824 considerava que libertos e ingênuos ${ }^{1}$ eram cidadãos brasileiros e, como tais, tinham direito à educação pública e gratuita.

Observa-se que, naquele período, mesmo sendo cidadãos, os negros que deixaram de ser escravizados não tinham direito ao voto, o que nos mostra como era limitada a cidadania da população negra, agravada pelo Decreto no 1.331 , de 17 de fevereiro de 1854, que proibia a admissão de escravizados nas escolas públicas do País (Cunha, 2004): "Art. 69 - Não serão admittidos à matricula, nem poderão frequentar as escolas: $₫ 1^{\circ}$ Os meninos que padecerem molestias contagiosas. $\$ 2^{\circ}$ Os que não tiverem sido vaccinados. $\$ 3^{\circ}$ Os escravos" (Decreto $\left.\mathrm{n}^{\circ} 1.331,1854\right)$. O Decreto $\mathrm{n}^{\circ}$ 7.031-A, de 6 de setembro de 1878 estabelecia que, no Município da Corte, "Art. $5^{\circ}$ - Nos cursos nocturnos poderão matricularse, em qualquer tempo, todas as pessoas do sexo masculino, livres ou libertos, maiores de 14 annos". Isto é, os negros só poderiam estudar no período noturno.

No século XIX, período em que as teorias racistas estavam em voga, a resistência à escolarização da população negra refletia, por um lado, a "descrença em sua capacidade intelectual" e, por outro, o temor de insurgência antes e, principalmente, após a Abolição. Uma explicação de ordem econômica para o veto à escolarização era o fato de que, ao saírem para a escola, os escravizados deixariam de produzir para os "senhores". A campanha abolicionista, no fim do século XIX, mobilizou vários setores da sociedade brasileira. Lopes (1995) assinala que o processo de libertação dos escravizados não se deu por uma forma humanística da elite brasileira, mas da emergência da reestruturação produtiva,

$1 \mathrm{O}$ ingênuo poderia ser criado pela mãe escrava até os 8 anos, e o senhor poderia, a partir de então, entregá-lo ao governo em troca de títulos da dívida pública resgatáveis em 30 anos ou explorar sua mão de obra até os 21 anos. 
cujo fim do regime servil de trabalho era pré-condição. Ou seja, no pós-Abolição, não houve uma orientação destinada a integrar os negros às novas regras de uma sociedade baseada no trabalho assalariado e na educação.

Após a Abolição, em 1888, e a Proclamação da República, em 1889, seguiu-se um período de tensão no qual ex-escravizados e seus descendentes procuravam distanciar-se do passado da escravidão. Observa-se que, no período de transição do Império para a República, tem início uma preocupação com a manutenção da "ordem" que, segundo temiam as elites da época, poderia ser interrompida devido à libertação dos escravizados. A educação dos negros nesse período (fim do século XIX) era pensada como treinamento para o trabalho (Lopes, 1995).

Como focalizado até aqui, não se pode afirmar que, no período reexaminado, houve uma preocupação, por parte das elites governantes, em relação à promoção da escolarização dos negros. Mas, a despeito dessa crítica, o que a população negra viu nas primeiras décadas republicanas foi a consolidação de projetos sociopolíticos excludentes e da ideia de raça como critério de classificação social e justificativa para a desigualdade. Com o fim do período escravagista, o projeto de educação da população negra para o trabalho foi posto em segundo plano, pois a mão de obra negra passou a ser substituída pela mão de obra dos imigrantes europeus, cuja vinda para o País fora estimulada pelo governo, para evitar os "problemas sociais" e econômicos causados pela abolição do trabalho dos escravizados, além da ideia de "branqueamento" da população brasileira.

A população negra no país, contudo, não permaneceu passiva, à espera de oportunidades educacionais, nos primeiros anos da República. Segmentos da população negra impedidos de participar de instituições dirigidas por brancos receberam instrução de pessoas escolarizadas bem como foram criadas organizações para lutar contra as desigualdades raciais nas primeiras décadas republicanas. Por exemplo, espaços como terreiros de candomblé contribuíram para o desenvolvimento da população negra e a preservação de valores culturais.

Ante tal situação, uma parte deles não permaneceu passiva. Pelo contrário, levou avante múltiplas formas de protesto, impulsionando os movimentos de mobilização racial (negra) no Brasil. Foram engendradas diversas organizaçôes com base na identidade racial; elas procuravam projetar os "homens de cor", como atores políticos, no cenário urbano (Domingues, 2007, p. 120).

Ainda de acordo com Domingues (2007),

$\mathrm{Na}$ primeira fase do movimento negro na era republicana (1889-1937), emergiram organizações de perfis distintos: clubes, grêmios literários, centros cívicos, associaçôes beneficentes, grupos "dramáticos", jornais e entidades políticas. [...] $\mathrm{Na}$ segunda fase 
(1945-1964), o Movimento Negro retomou a atuação no campo político, educacional e cultural. [...] Na terceira fase (1978-2000), surgiram dezenas, centenas de entidades negras, sendo a maior delas o Movimento Negro Unificado (p. 121).

Sem espaço de maior projeção para debater suas questões, denunciar episódios de discriminação racial, a população negra, por meio de seus "intelectuais negros", fundaram vários jornais a partir da primeira década do século XX. Nesse aspecto, era comum encontrar nesses jornais denúncias sobre racismo bem como denúncias ao descaso das escolas em relação às crianças negras. Um dos intelectuais que atuaram contra o racismo e pela promoção da população negra à frente de um destes jornais (A Província; O trabalho) foi Manuel Quirino. Ele acreditava que a falta de oportunidades, não a desigualdade natural, criava as assimetrias entre brancos e negros.

Creditava-se à educação um fator de promoção de igualdade (Cruz, 2009). Entende-se que, além de a inserção da população negra no contexto educacional formal ocorrer de forma lenta, essa não significou, contudo, uma adaptação dos conteúdos trabalhados a esse público. Por muito tempo, e ainda vigora, um currículo referenciado na matriz cultural europeia (Araújo, \& Silva, 2020). No entanto, isso não impediu que a população negra seguisse criando alternativas de enfrentamento à exclusão que garantiram nossa sobrevivência cultural. Nessa direção, Gomes (2011) assinala que

O Teatro Experimental do Negro (TEN) foi fundado na cidade do Rio de Janeiro em 1944, no final da vigência do Estado Novo, pelo intelectual negro Abdias do Nascimento, exintegrante da Frente Negra Brasileira. Tinha por objetivo, além de produzir peças teatrais, motivar o negro, através da alfabetização, a combater a discriminação e o preconceito racial. Funcionava em sede emprestada pela União Nacional dos Estudantes, na Praia do Flamengo. O responsável teórico do grupo foi Guerreiro Ramos (1915-1982) (p. 137).

Vale ressaltar que "Abdias Nascimento organizou em 1949 a Convenção e a Conferência do Negro, em São Paulo e no Rio de Janeiro, respectivamente" (Gomes, 2009, p. 143).

Ainda de acordo com Gomes (2011),

Se no I Congresso Nacional do Negro, realizado na capital do Rio Grande do Sul, não identificamos nenhum intelectual que tenha atuado diretamente na Frente Negra, certamente a proposta firmada neste oásis, intitulada "Campanha Nacional de Alfabetização", somente foi possível devido a esta reivindicação ser uma constante preocupação do movimento frentenegrino. A educação era considerada o maior instrumento para a conscientização e elevação social do negro brasileiro, proposta também evidenciada no Teatro Experimental do Negro, de Abdias do Nascimento (p. 143). 
Até a década de 1950, circulava no Brasil a tese da "democracia racial". Foi nesse contexto que se destacam trabalhos sobre a questão racial no Brasil. Ferreira (2010) sublinha que, as inovações enunciadas por Florestan Fernandes, nas Ciências Sociais e no estudo das relaçôes raciais no Brasil, foram de grande valia para o movimento negro na sua luta contra a opressão e as desigualdades impingidas ao negro e na luta pela defesa de sua cidadania. "No entanto, tais ideias não ficaram sem crítica por parte das lideranças do movimento negro, pois a ênfase dos seus estudos supunha que as desigualdades raciais eram um epifenômeno da luta de classes" (Ferreira, 2010, p. 40). Assim, a chamada "sutileza" do racismo brasileiro vem sendo confrontada e desvelada, desde os estudos de Florestan Fernandes (Ferreira, 2010).

Telles (2003) frisa que, no período da ditadura militar no Brasil (1964-1985), e conforme os governos militares diminuíam a repressão contra acadêmicos na década de 1970, estudos sobre raça ressurgiam. No fim dos anos 1970, retornam ao Brasil pesquisadores como Carlos Hasenbalg e Nelson do Valle Silva. Após defenderem suas teses nos Estados Unidos, iniciaram uma nova etapa da pesquisa sobre relações raciais na universidade brasileira, acerca de raça, classe e desenvolvimento capitalista. Esses pesquisadores enfocaram o efeito do desenvolvimento capitalista e a industrialização nas desigualdades raciais.

Por sua vez, Carvalho (2004) sublinha "os processos através dos quais se produz, no ensino fundamental, o fracasso escolar mais acentuado entre crianças negras do sexo masculino, conforme vêm indicando as estatísticas educacionais brasileiras há algumas décadas" (p. 247). A hipótese levantada pela autora foi de que, "pelo menos no âmbito da escola, a identidade racial de meninos e meninas seria construída tendo como referência não apenas características fenotípicas e status socioeconômico, mas também seu desempenho escolar" (Carvalho, 2004, p. 247).

O que essa literatura não tem abordado com a devida profundidade é o fato de que, no grupo daqueles que fracassam na escola, ou frente aos quais a escola fracassa em ensinar, os meninos são em número maior que as meninas e dentre os meninos, os negros em maior proporção que os brancos (Carvalho, 2004, pp. 267,268).

Munanga (2005) dá ênfase aos múltiplos discursos referente à tensão entre o papel que a escola tem desempenhado na reprodução do racismo e o papel que deveria desempenhar no combate ao racismo. O autor propôs a defesa da inclusão social e o combate à exclusão social, étnica e racial. Essa discussão traz para seu campo questões referentes à própria dinâmica da sociedade brasileira, desde os tempos coloniais, como as que dizem respeito às práticas de racismo no espaço educacional. Por exemplo, e de acordo com informações que constam do Portal 
G1-Globo, de 14 de março de 2018 (Arcoverde, \& Fiúza, 2018), apreende-se que o Estado de São Paulo registra um caso de injúria racial em estabelecimentos de ensino a cada cinco dias. Os estabelecimentos de ensino abrangem instituições de ensino fundamental, médio e superior. Em 2016, foram 1.576 boletins de ocorrência de injúria racial, sendo 75 em estabelecimentos de ensino. Em 2017, o número caiu para 1.297 boletins, sendo 67 em escolas ou universidades. Nessa direção e segundo ainda a reportagem, o professor de direito do Instituto Luís Gama, Sílvio Almeida, diz que os números revelam o "aspecto estrutural" do racismo. "Racismo dá o tom de normalidade das instituições e da vida social em uma sociedade desigual" (Almeida apud Arcoverde, \& Fiúza, 2018).

Os estudos que se dedicam a analisar as questões raciais e étnicas no Brasil são fundamentais porque buscam, na educação, referenciais que possam ampliar a visibilidade sobre tais questôes. Por exemplo, Teles (2003, p. 198) assinala que "a péssima distribuição de renda no Brasil espelha uma imensa desigualdade na educação [.. .] os trabalhadores são remunerados de acordo com suas aptidóes e conhecimento e, portanto, mais educação significa maior renda”.

Esse contexto apresentado de histórias de mobilizações fez com que a sociedade brasileira, principalmente no período democrático recente, século XXI, se reconhecesse como uma sociedade em que o racismo e as desigualdades raciais estão presentes. Como consequência do exposto, pudemos perceber o caráter crônico das desigualdades raciais na área de educação ao longo dos anos, o que significa que as políticas de caráter universalistas, cujos efeitos foram percebidos ao longo de décadas, não foram eficazes para desconstruir as desigualdades raciais constatadas. Essa constatação, como apontam Silva e Silvério (2003, p. 17), "Coloca na ordem do dia a premência de políticas afirmativas para democratizar o acesso e permanência no ensino superior dos grupos fragilizados econômica e socialmente". Vale lembrar que,

No campo legal, o lento processo de luta antirracista começou com a Lei no 1.390/1951, que tornou contravenção penal a "prática de atos resultantes de preconceitos de raça ou de cor", e culminou na determinação pela Constituição de 1988 de que "a prática do racismo constitui crime inafiançável e imprescritível, sujeito à pena de reclusão, nos termos da lei” (art. 5º, XLII) (Constituição da República Federativa do Brasil, 1988).

Contudo, observa-se também que, somente no ano de 2003, a legislação brasileira implementou a Leis $n^{\circ} 10.639$, e, em 2008, a Lei $n^{\circ} 11.645$, que instituíram a obrigatoriedade, na educação básica brasileira, do ensino de História e Cultura Afro-Brasileira e Indígena no Brasil. As leis refletem a tensão presente na história das políticas educacionais do País, pois, de um lado, há políticas que visam à permanência do racismo estrutural que se revela pela invisibilidade da 
raça e pelo mito da democracia racial e, de outro, políticas frutos de lutas sociais que rompem com as primeiras. Merece destaque outras importantes legislações, como o Estatuto da Igualdade Racial, aprovado pela Presidência da República, em 2010. O Estatuto foi sancionado em 20 de julho de 2010, na forma da Lei ${ }^{\circ}$ 12.288, por sua vez, o Decreto $n^{\circ} 8.136 / 2013$, aprova o regulamento do Sistema Nacional de Promoção da Igualdade Racial (Sinapir), instituído pelo Estatuto de 2010 .

Outra importante legislação para a população negra no Brasil se refere à Lei no 12.711/2012, a chamada "Lei das Cotas". A norma dispõe sobre o ingresso de estudantes nas universidades federais e nos institutos federais de educação, ciência e tecnologia, assim, ampliando novas possibilidades quanto à inclusão nesse grau de ensino para grupos sociais historicamente dele excluídos, bem como a Lei $n^{\circ}$ 12.990/2014, que reserva aos negros $20 \%$ das vagas oferecidas nos concursos públicos para provimento de cargos efetivos e empregos públicos no âmbito da Administração Pública Federal, das autarquias, das fundações públicas, das empresas públicas e das sociedades de economia mista controladas pela União, além da Portaria Normativa no 4, de 2018, que regulamenta o procedimento de heteroidentificação complementar à autodeclaração dos candidatos negros (pretos e pardos), para fins de preenchimento das vagas reservadas nos concursos públicos federais, nos termos da Lei no 12.990/2014. Nessa direção, Mello e Resende (2019, p. 161) chamam a atenção para "que o percentual de $20 \%$ para negras/os seja cumprido, inclusive nos concursos para docentes", no ensino superior no País. Indicamos que, ao mesmo tempo em que tais legislações são fundamentais para a superação de desigualdades, elas somente se efetivam pela ação e força dos sujeitos e dos movimentos sociais.

\section{METODOLOGIA}

Para este estudo, utiliza-se dos aportes metodológicos de Thompson (2011). Para o autor, esses pressupostos são aqueles que dizem respeito à forma como o conhecimento é construído. Thompson (2011) desenvolve um referencial metodológico que se fundamenta na hermenêutica de profundidade (HP) como método para a investigação sócio-histórica e parte do suposto que o objeto sob análise é uma construção simbólica significativa que exige uma interpretação.

Essa metodologia da HP prevê três fases: análise sócio-histórica, análise formal ou discursiva e interpretação/reinterpretação. A primeira etapa da HP é a análise sócio-histórica. Nessa etapa, objetiva-se reconstruir as condições sociais e históricas de produção e circulação das formas simbólicas. 
A segunda etapa da HP, denominada análise formal ou discursiva, refere-se ao estudo das formas simbólicas que circulam nos campos sociais, as quais, por serem complexas, apresentam uma estrutura articulada que necessita de análise própria. Além disso, temos elegido a análise de conteúdo (AC), proposta por Bardin (2011). Esse procedimento possibilita mostrar ao leitor o caminho percorrido na análise. Isto é, oferece uma descrição sistemática e objetiva da organização interna das formas simbólicas, bem como a obediência aos princípios éticos na pesquisa.

A última etapa da HP, interpretação/reinterpretação, construiu-se a partir das fases anteriores de análise sócio-histórica e análise formal ou discursiva. Ou seja, busca-se sintetizar e explicar criativamente o que foi dito para chegar a possíveis significados.

Isso posto, apresentamos a seguir as formas simbólicas investigadas: estudos sobre relações étnico-raciais e desigualdades raciais no Brasil e suas análises.

\section{ESTUDOS SOBRE RELAÇŌES ÉTNICO-RACIAIS}

Estudos têm se proposto a corroborar com esse campo ao definir e questionar conceitos, identificar problemas, elaborar propostas e aplicar o conhecimento produzido sobre o assunto para promover a diminuição dessas desigualdades. Trata-se de um campo em expansão no Brasil, atestado pelos indicadores da produção acadêmica. Vale mencionar o Repertório bibliográfico sobre a condiçãa do negro no Brasil (Cavalcante et al., 2017), publicado pela Edições Câmara, em versões impressa e eletrônica. Esse livro reúne uma bibliografia abrangente e diversificada sobre a condição do negro no Brasil e que teve como proposta, entre outras, facilitar o acesso de legisladores, pesquisadores e cidadãos em geral a um conjunto de textos significativos que informam, debatem, analisam, refletem e denunciam a condição do negro ao longo da história do Brasil, da colonização até os dias atuais.

$\mathrm{Na}$ Contemporaneidade, no Brasil, as políticas de ações afirmativas que fazem parte das discussões internas do Movimento Negro desde a década de 1980 passaram a ocupar um lugar de destaque em sua pauta de reivindicações (Artes, 2015) como demonstrou o Repertório (Cavalcante et al., 2017). Essas mudanças atingem também o plano acadêmico com a criação da Associação Brasileira de Pesquisadores/as Negros/as (ABPN). Merece destaque o Congresso de Pesquisadores Negros (Copene), promovidos pela Associação. A ABPN realiza o Copene a cada dois anos, tendo este surgido da mesma conjuntura histórica das relações raciais na sociedade contemporânea e da ampliação de acadêmicos 
negros oriundos do Movimento Negro que se qualificaram nas décadas de 1980 e 1990. Em outubro de 2018, houve a décima edição do Copene, na Universidade Federal de Uberlândia (UFU), no Estado de Minas Gerais. O X Copene teve como tema "Reexistência intelectual negra e ancestral: 18 anos de enfrentamento".

Atualmente, inúmeros grupos de pesquisa estão registrados no Conselho Nacional de Desenvolvimento Científico e Tecnológico (CNPq), bem como de Núcleos de Estudos Afro-Brasileiros (Neabs), a ABPN é uma rede de articulação nacional que divulga Núcleos de Estudos Afro-Brasileiros, os NEABS, que participam das lutas, reivindicações e fomento à pesquisa que envolvem o campo das relações raciais. Assim, no âmbito deste estudo, realizamos um levantamento em bases de dados, que nos permite observar uma produção crescente. Em primeiro lugar, realizamos um levantamento inicial na Revista da ABPN, entre 2010 e 2013. Para tanto, utilizamos os seguintes descritores: "pesquisador/es negro/s; desigualdades". Nesse aspecto, localizamos cinco artigos relacionados (Aquino, Santana, Santana, \& Silva Júnior, 2013; Cardoso, 2013; Müller, \& Coelho, 2013; Reis, 2010; Schucman, Costa, \& Cardoso, 2012).

Com efeito, desse universo, duas publicações receberam uma análise mais apurada por focalizarem trajetórias do movimento de pesquisadores negros e identidade racial do pesquisador, e estão descritas a seguir. Cardoso (2013) preocupou-se em entender a trajetória do movimento de pesquisadores e pesquisadoras negros no contexto da luta antirracista no interior da universidade brasileira, de um lado, propõe a ampliação do leque de parceiros no interior da universidade, nos vários campos da ciência e articulá-los a causa da igualdade, de outro, assinala que essa aproximação com demais temas podem contribuir para garantir o protagonismo dos pesquisadores negros no País. Schucman et al. (2012) refletiram sobre a paridade ou assimetria racial em pesquisas acerca de relações raciais. As experiências dos autores demonstraram que tanto a paridade racial quanto a assimetria racial na interação dos pesquisadores com os diferentes sujeitos nos estudos de relações raciais podem ser importantes para emergir diferentes aspectos das relaçôes raciais brasileiras.

Em segundo lugar, utilizamos os mesmos descritores "pesquisador/es negro/s; desigualdades" para análise da base de artigos acadêmicos no banco da Scielo. No conjunto de títulos localizados nessa base de dados (1987-2013), encontramos 21 artigos. Porém vale ressaltar que localizamos somente um artigo cujo descritor "pesquisador/es negro/s" constava no título do artigo, A formação de pesquisadores negros no Brasil: plano 500 de política cientifica nacional, de Cunha Júnior (2003). Para o autor, os estudantes negros que ingressam na pós-graduação encontram poucos orientadores que trabalham ou conhecem o tema das relações raciais, o 
que impõe dificuldades ao projeto de pesquisa e à trajetória do aluno ou aluna. Muitas vezes, não há grupos de estudo ou disciplinas que dariam sustentação ao projeto.

Tabela 1 - Características predominantes de produção acadêmica brasileira referente aos descritores "pesquisador/es negro/s; desigualdades" (1987-2013)

\begin{tabular}{lll}
\hline \multicolumn{2}{c}{ Características predominantes } & $\%$ \\
\hline Sexo dos autores & Masculino & 56 \\
& Feminino & 44 \\
Período de publicação & Até 2000 & 4,9 \\
& $2001-2005$ & 23,8 \\
& $2006-2010$ & 33,3 \\
Local de publicação do & Bahia & 38 \\
periódico & Minas Gerais & 9,5 \\
& Paraíba & 9,5 \\
& Paraná & 4,7 \\
& Rio Grande do Sul & 4,7 \\
texto & Rio de Janeiro & 4,7 \\
Quantidade em que o & Uma vez & 4,7 \\
& Santa Catarina & 52,4 \\
& São Paulo & 52,5 \\
& Duas vezes & 23,8 \\
& Três vezes & 9,5 \\
& Quatro ou mais & 14,2 \\
& vezes & \\
\hline
\end{tabular}

Fonte: elaborado pelo autor, com base em dados da Scielo e banco de dados da pesquisa.

Observa-se que a produção acadêmica é recente (apenas um título registrado com data anterior a 2000), elaborada, em sua maioria, por autores do sexo masculino (56\%). Pode-se observar que os artigos são predominantemente publicados na última década, entre 2000 e 2010 (62\%), continuando em crescimento (38\%) no período de 2011 a 2013. Observa-se também que a Região Sudeste do Brasil é a que mais publica, destaque para o Estado de São Paulo (52,4\%). Por fim, nota-se que o descritor "pesquisador negro" é focalizado 
pelo menos uma vez nos artigos (52,5\%).

Tabela 2 - Subtemas referentes a "pesquisador negro" nos artigos do Scielo (1987-2013)

\begin{tabular}{ll}
\hline \multicolumn{1}{c}{ Temas } & \multicolumn{1}{c}{$\%$} \\
\hline Associação (ABPN) & 34,5 \\
Demanda & 6,9 \\
Desigualdades sociais & 3,5 \\
Estratégia & 12,0 \\
Formação & 17,2 \\
Movimentos sociais & 3,5 \\
Profissionalização e mercado de & 3,5 \\
trabalho & 12,0 \\
Trajetória e produção acadêmica & 6,9 \\
Visibilidade & \\
\hline
\end{tabular}

Fonte: elaborado pelo autor, com base em dados da Scielo e banco de dados da pesquisa.

Quando nosso levantamento propôs focalizar o contexto em que o descritor "pesquisador negro" era destaque, constata-se, pelas informações da tabela 2, que $34,5 \%$ se referem ao contexto da $\mathrm{ABPN}$, e apenas 3,5\%, estão relacionados à questão da desigualdade social no Brasil. Nessa direção, Cunha Júnior (2003) chama a atenção para a necessidade de formação de "pesquisadores negros", pessoas raramente encontradas nas diversas áreas de pesquisa, situação que pode produzir uma sub-representação étnica nas variadas esferas de decisão do Estado.

Para Cunha Júnior (2003):

A necessidade de formação de pesquisadores negros vem da quase total ausência nossa nas diversas áreas de pesquisa, produzindo uma sub-representação étnica nas variadas esferas da decisão do estado. As decisões em políticas públicas, da federação, dos estados e dos municípios, são fortemente orientadas e vinculadas às pesquisas cientificas e tecnológicas produzidas nas universidades e centros de pesquisas.

Ao pesquisar trajetórias de pesquisadores negros e homens e mulheres (negros, negras) com titulação de mestre ou mestra na pós-graduação no País, Silva (2016) frisa que, na opinião desses, a categoria pesquisador negro traz, por um lado, uma ancestralidade, uma origem, mas que independem do fenótipo do pesquisador. Por outro, carrega um comprometimento político, um "ativismo acadêmico" como uma ferramenta para a luta de transformação antirracista, quase sempre realizada por negros, homens e mulheres.

Santos (2011) sustenta o surgimento de uma nova categoria de intelectuais 
no Brasil: os negros intelectuais. Com base em seus perfis, trajetórias e condutas político-acadêmicas, defende-se a hipótese do surgimento dessa nova categoria de intelectuais na academia brasileira. "Estes são os(as) intelectuais de origem ou ascendência negra que sofreram ou sofrem influência direta ou indireta dos movimentos sociais negros, adquirindo ou incorporando destes uma ética da convicção antirracismo" (Santos, 2011, p. 102).

Guimarães (2004), por sua vez, informa que existiram "intelectuais negros" não apenas no meio acadêmico, mas nos meios artístico, cultural e político, entre outros. No entanto, pode-se dizer que, "em se tratando de academia no Brasil, de fato, em geral, os negros intelectuais historicamente têm sido excluídos deste espaço" (Santos, 2011, p. 4). Como se observa, no passado e no presente, há barreiras raciais nas universidades brasileiras que impedem intelectuais de almejarem posições acadêmicas. Conforme destaca Carvalho (2007): “é um fato histórico, portanto, que a universidade pública no Brasil foi instalada explicitamente sob o signo da brancura. Enquanto esse pressuposto não for criticado e revisado, continuaremos partícipes desse ato racista inicial" (Carvalho, 2007, p. 96).

Porém, na Contemporaneidade, ainda oscilam algumas discussóes sobre o acesso do negro à universidade, nos níveis mais elevados de formação educacional, à educação superior, seja como aluno ou professor. Podemos citar como exemplo o episódio em que o professor e pesquisador Kabengele Munanga havia sido preterido na seleção de pesquisadores beneficiados pela bolsa do programa "Professor Visitante Nacional Sênior", isto é, apesar de toda a sua experiência e trajetória intelectual. O episódio resultou em protestos da comunidade acadêmica e de ativistas e pesquisadores do Movimento Negro. Vale ressaltar que, após protestos de entidades de classe e de lideranças do Movimento Negro e do mundo acadêmico, o professor foi incluso no programa (Afropress, "Depois de protestos...”, 2014). Entende-se que há um longo caminho a percorrer para que a paridade cor/raça se torne uma realidade na educação superior, especialmente na pós-graduação.

\section{DESIGUALDADE RACIAL NO BRASIL}

Estudos quantitativos e qualitativos sobre a desigualdade racial no Brasil continuam a ser produzidos, servindo como um constante lembrete das injustiças raciais do Brasil. Nesse aspecto, pode-se citar como exemplo o Relatório anual das desigualdades raciais no Brasil: 2009-2010, de Paixão, Rossetto, Montovanele e \& Carvano (2010), que indicam assimetrias por cor/raça e distribuição por sexo em diferentes aspectos: saúde, assistência social, vitimização, previdência 
social e acesso aos sistemas de ensino. Esses estudos demonstram que as desigualdades raciais no País não apenas são expressivas, como extremamente persistentes ao longo do tempo. A dimensão e a persistência das desigualdades raciais no Brasil não podem ser explicadas unicamente pelas diferentes condições socioeconômicas, mas por uma concepção de racismo que integra as dimensões estrutural e simbólica na produção e reprodução das desigualdades raciais no Brasil (Rosemberg, Bazilli, \& Silva, 2003).

Outro levantamento inicial realizado no banco de teses da Capes, entre 2011 e 2012, orientado pelos descritores "desigualdades educação; negros", "desigualdades educacionais; negros", "desigualdade educação; raça" "desigualdade educacional; raça", localizou 50 dissertaçōes e teses (12 teses e 38 dissertaçôes). De maneira geral, as teses e dissertaçôes defendidas comprovam e fazem frente contra as desigualdades educacionais da população negra na sociedade brasileira, em especial no sistema educacional. Essas pesquisas significativas informam, debatem, analisam, refletem e denunciam a condição do negro ao longo da história do Brasil, da colonização até os dias atuais. As teses e dissertações defendidas corroboram a existência das desigualdades educacionais da população negra na sociedade brasileira. Os estudos apontaram, particularmente, algumas tendências: programas de ação afirmativa na educação superior brasileira (Carvalho, 2011), gênero, raça e escolarização (Mello, 2011), desigualdade racial e mobilidade social no Brasil (classe, família e racismo) (Andrade, 2012).

Entende-se que, nas últimas décadas, houve o impulso de uma série de iniciativas nacionais e internacionais no plano internacional. Citamos a Conferência de Durban contra o Racismo, em 2001, em Durban, África do Sul. No plano nacional, entre outras ações, destacamos o Estatuto da Igualdade Racial (Lei $\left.\mathrm{n}^{\circ} 12.288,2010\right)$. Observa-se, ainda, o desenvolvimento de programas de valorização da cultura e da história negra (Alves, 2011), os estudos sobre racismo, racismo institucional e o preconceito que, em conjunto, mantêm a população negra concentrada nos segmentos mais baixos da estratificação social brasileira (Pace, 2012). Focalizam-se também os estudos sobre a mobilidade educacional dos negros (Benevides, 2012). Neste último, Silva (2016) assinala que a presença negra na universidade, além de reduzida, é desigual e restrita a algumas áreas.

As hierarquias sociais de gênero e raça se expressam na distribuição dos discentes por áreas de conhecimento: as mulheres e os negros estão presentes nas áreas consideradas de menor prestígio social e econômico, como a Educação, as Humanidades e as Artes. Na Educação, por exemplo, são 479 mulheres graduadas para cada grupo de 100 homens, enquanto nas Engenharias são 29 engenheiras para cada grupo de 100 engenheiros. No recorte de cor/ raça, a maior participação encontrada está também na área da Educação, porém bastante restrita: são 53 negros para cada grupo de 100 brancos, considerando o grupo de graduados, e 24 para os doutores (Fundação Carlos Chagas, 2016, p. 5). 
Entende-se que prestígio pode ser associado à relação candidato-vaga no vestibular, ao potencial de ganho na carreira, às carreiras imperiais ou à hierarquia social das profissões, conforme Fundação Carlos Chagas (2016).

\section{CONSIDERAÇÕES FINAIS}

Este artigo propôs chamar a atenção para as desigualdades educacionais da população negra no Brasil e serviu para alicerçar a revisão de literatura, entre outros estudos, da construção de um dos eixos da tese de doutorado aqui já mencionada. A revisão de literatura facilita o acesso de pesquisadores e cidadãos em geral a um conjunto de pesquisas que captam, descrevem, discutem e denunciam a condição da população negra ao longo da história do Brasil. Entende-se que o papel da pesquisa na elaboração e avaliação de políticas públicas possibilita instrumentalizar atores sociais, especialmente os alijados de posiçôes vantajosas, em particular os negros, para participarem de negociações com o maior acervo de conhecimento possível. Configura-se, pois, um compromisso ético e político da pesquisa.

A desigualdade e a pobreza têm cor no Brasil e fazem com que nossas políticas sociais, supostamente universais, terminem por obter resultados insuficientes, visto que não contribuem para a superação dessa ordem de desigualdade. Temos crescimento econômico, científico e tecnológico. Porém as desigualdades sociais continuam sendo uma marca da sociedade brasileira. Por um lado, no País, os direitos conquistados pela população negra, com a promulgação da Constituição Federal de 1988 e do Estatuto da Igualdade Racial, representam um salto de qualidade no tratamento dado pelo Estado brasileiro à questão da igualdade racial. Por outro lado, há denúncias de casos de racismo quase que diariamente na mídia, universidade, trabalho, além da produção acadêmica de períodos mais recentes, de que se apreende que a população negra se encontra em situação de desvantagem na sociedade em questões como saúde, moradia, saneamento básico, emprego e renda, encarceramento, educação, segurança, entre outras (Cavalcante et al., 2017; Paixão et al., 2010; Portaria Normativa no 4, 2018).

Esses estudos reforçam a necessidade da sequência de implementações de políticas de ação afirmativas para a população negra no País. Políticas essas que possam garantir uma maior equidade de oportunidades e de padrão de vida que alterem a situação de desigualdade e possibilitem a inclusão da população negra nos segmentos mais dinâmicos no sistema educacional e de maior renda no mercado de trabalho. Acreditamos que este trabalho possa ser uma contribuição oportuna, reforçando o compromisso com a promoção da igualdade racial no País. 


\section{REFERÊNCIA}

Alves, C. D. (2011). A implementação da Lei 10.639/2003 nas escolas da rede municipal do Recife e o papel da gestão escolar entre a formulação e as práticas: impasse e perspectiva. (Dissertação de Mestrado). Universidade Federal de Pernambuco, Recife.

Andrade, F. J. (2012). Classe, raça e ação afirmativa: a politica de inclusão social numa universidade pública de Pernambuco. (Tese de Doutorado). Universidade de São Paulo, São Paulo.

Aquino, M., Santana, S., Santana, L., \& Silva Júnior, J. F. (2013, fevereiro). Temas sobre o/a negro/a: uma análise da produção de conhecimento no Curriculum Lattes. Revista da ABPN, 5(11). Recuperado a partir de https:// abpnrevista.org.br/index.php/site/article/view/243

Araújo, D. P., \& Silva, M. A. B. (2020). O ensino da História e Cultura AfroBrasileira e Indígena no currículo dos cursos de Pedagogia de duas instituições de ensino superior. Arquivo Brasileiro de Educação, 8(17), 322-351. Recuperado a partir de https://doi.org/10.5752/P.2318-7344.2020v8n17p322-351

Arcoverde, L., \& Fiúza, R. (2018, 14 março). Escolas e universidades de SP têm um caso de injúria racial a cada cinco dias. Portal G1 São Paulo. Recuperado a partir de https://g1.globo.com/sp/sao-paulo/noticia/escolas-e-universidadesde-sp-tem-um-caso-de-injuria-racial-a-cada-cinco-dias.ghtml

Artes, A. (2015). Desigualdade de cor/raça e sexo entre estudantes e titulados na pósgraduação brasileira 2000 e 2010. (Relatório de Pesquisa). Projeto Equidade na Pós-Graduação, Fundação Carlos Chagas, São Paulo.

Bardin, L. (2011). Análise de conteúdo. L. A. Reto, \& A. Pinheiro (Trads.). Lisboa: Edições 70.

Benevides, D. F. (2012). O que você vai ser quando você crescer? O negro e a universidade. (Dissertação de Mestrado). Universidade do Estado da Bahia, Salvador.

Cardoso, P. J. F. (2013, outubro). Luta antirracista na educação: o movimento de pesquisadores negros e pesquisadoras negras - anotaçôes de viagem. Revista da ABPN, 5(11), 119-130. Recuperado a partir de https://abpnrevista.org.br/ index.php/site/article/view/192

Carvalho, C. M. (2011). Por uma perspectiva critica de direitos humanos: o caso 
das cotas para a população negra no acesso ao ensino superior público. (Dissertação de Mestrado). Universidade de São Paulo, São Paulo.

Carvalho, J. J. (2007). O confinamento racial do mundo acadêmico brasileiro. PADE $, 1(1), 31-50$. Recuperado a partir de https://www.publicacoesacademicas. uniceub.br/pade/article/view/144

Carvalho, M. P. (2004). O fracasso escolar de meninos e meninas: articulações entre gênero e cor/raça. Cadernos Pagu, 22, 247-290. Recuperado a partir de https://dx.doi.org/10.1590/S0104-83332004000100010

Cavalcante, R., \& Estrêla, C. (Coords.), Ferreira, J., \& Suganuma, S. (Orgs.), Arruda P. et al. (Col.). (2017). Repertório bibliográfico sobre a condição do negro no Brasil. Brasília: Câmara dos Deputados, Ediçôes Câmara, 2017. (Série fontes de referência, 1, PDF). Recuperado a partir de https://bd.camara.leg. $\mathrm{br} / \mathrm{bd} /$ bitstream/handle/bdcamara/34741/repertorio_bibliografico_condicao. pdf?sequence $=5$ \&isAllowed $=y$

Constituição da República Federativa do Brasil (1988). (1988). Diário Oficial da União, Brasília.

Constituição Política do Imperio do Brazil, de 25 de março de 1824. (1824). Coleção das Leis do Império do Brasil de 1824, Rio de Janeiro. Recuperado a partir de http://www.planalto.gov.br/ccivil_03/constituicao/constituicao24. htm

Cruz, R. A. (2009). Negros e educação: as estratégias de dois professores da Faculdade de Direito de São Paulo nos séculos XIX e XX. (Dissertação de Mestrado). Pontifícia Universidade Católica de São Paulo, São Paulo.

Cunha Júnior, H. A. (2003). A formação de pesquisadores negros no Brasil: Plano 500 de Política Científica Nacional (uma proposta de um pesquisador militante). Revista Espaço Acadêmico, 3(27).

Cunha, P. M. C. (2004). Educação como forma de resistência: o caso da Irmandade de Nossa Senhora do Rosário e São Benedito dos Homens Pretos. (Dissertação de Mestrado). Universidade Federal Fluminense, Rio de Janeiro.

Decreto $\mathrm{n}^{\circ}$ 1.331-A, de 17 de fevereiro de 1854. (1854, 17 fevereiro). Approva o Regulamento para a reforma do ensino primario e secundario do Municipio da Côrte. Coleção de Leis do Império do Brasil - 1854, 1(1). Recuperado a partir de http:/www2.camara.leg.br/legin/fed/decret/1824-1899/decreto-1331-a17-fevereiro-1854-590146-publicacaooriginal-115292-pe.html 
Decreto no 7.031-A, de 6 de setembro de 1878. (1878, 6 setembro). Crêa cursos nocturnos para adultos nas escolas publicas de instrucção primaria do $1^{\circ}$ gráo do sexo masculino do municipio da Côrte. Coleção de Leis do Império do Brasil - 1878, 1, 711. Recuperado a partir de http://www2.camara.leg. br/legin/fed/decret/1824-1899/decreto-7031-a-6-setembro-1878-548011publicacaooriginal-62957-pe.html

Decreto no 8.136, de 5 de novembro de 2013. (2013, 5 novembro). Aprova o regulamento do Sistema Nacional de Promoção da Igualdade Racial - Sinapir, instituído pela Lei no 12.288, de 20 de julho de 2010. Diário Oficial da União, Brasília. Recuperado a partir de https://www.planalto.gov.br/ccivil_03/_ ato2011-2014/2013/decreto/d8136.htm

Depois de protestos, CAPES volta atrás e classifica Munanga. (2014, 6 agosto). Afropress. Recuperado a partir de https://www.afropress.com/depois-deprotestos-capes-volta-atras-e-classifica-munanga/

Domingues, P. (2007). Movimento negro brasileiro: alguns apontamentos históricos. Tempo, 12(23), 100-122. Recuperado a partir de https://dx.doi. org/10.1590/S1413-77042007000200007

Ferreira, A. H. (2010). Discursos étnico-raciais proferidos por candidatos/as a programa de ação afirmativa. (Tese de Doutorado). Pontifícia Universidade Católica de São Paulo, São Paulo.

Fundação Carlos Chagas. (2016). Concurso de pesquisa: negras e negros nas Ciências: edital. São Paulo: FCC.

Gomes, A. (2011, julho-dezembro). Oásis e desertos no Brasil: da Frente Negra Brasileira aos congressos nacionais sobre a temática afro-brasileira e negra. Acervo, 22(2), 131-146. Recuperado a partir de http://revista.arquivonacional. gov.br/index.php/revistaacervo/article/view/13/13

Gomes, N. L., \& Rodrigues, T. C. (2018, outubro-dezembro). Resistência democrática: a questão racial e a Constituição Federal de 1988. Educação e Sociedade, 39(5), 929-945. Recuperado a partir de https://doi.org/10.1590/ ES0101-73302018200256

Guimarães, A. S. A. (2004, abril). Intelectuais negros e formas de integração nacional. Estudos Avançados, 18(50), 271-284. Recuperado a partir de http:// www.revistas.usp.br/eav/article/view/9986/11558 
Lei no 10.639, de 9 de janeiro de 2003. (2003, 9 janeiro). Altera a Lei no 9.394, de 20 de dezembro de 1996, que estabelece as diretrizes e bases da educação nacional, para incluir no currículo oficial da Rede de Ensino a obrigatoriedade da temática "História e Cultura Afro-Brasileira", e dá outras providências. Diário Oficial da União, Brasília. Recuperado a partir de http://www.planalto. gov.br/ccivil_03/leis/2003/L10.639.htm

Lei no 11.645, de 10 de março de 2008. (2008, 10 março). Altera a Lei no 9.394, de 20 de dezembro de 1996, modificada pela Lei $n^{\circ} 10.639$, de 9 de janeiro de 2003, que estabelece as diretrizes e bases da educação nacional, para incluir no currículo oficial da rede de ensino a obrigatoriedade da temática "História e Cultura Afro-Brasileira e Indígena”. Diário Oficial da União, Brasília. Recuperado a partir de http://www.planalto.gov.br/ccivil_03/_ato20072010/2008/lei/l11645.htm

Lei $n^{\circ}$ 12.288, de 20 de julho de 2010. (2010, 20 julho). Institui o Estatuto da Igualdade Racial; altera as Leis ${ }^{\text {os }} 7.716$, de 5 de janeiro de 1989, 9.029, de 13 de abril de 1995, 7.347, de 24 de julho de 1985, e 10.778, de 24 de novembro de 2003. Diário Oficial da União, Brasília. Recuperado a partir de http://www. planalto.gov.br/ccivil_03/_ato2007-2010/2010/lei/l12288.htm

Lei no 12.711, de 29 de agosto de 2012. (2012, 29 agosto). Dispóe sobre o ingresso nas universidades federais e nas instituições federais de ensino técnico de nível médio e dá outras providências. Diário Oficial da União, Brasília. Recuperado a partir de http://www.planalto.gov.br/ccivil_03/_ato20112014/2012/lei/l12711.htm.

Lei no 12.990, de 9 de junho de 2014. (2014, 9 junho). Reserva aos negros 20\% (vinte por cento) das vagas oferecidas nos concursos públicos para provimento de cargos efetivos e empregos públicos no âmbito da administração pública federal, das autarquias, das fundações públicas, das empresas públicas e das sociedades de economia mista controladas pela União. Diário Oficial da União, Brasília. Recuperado a partir de http://www.planalto.gov.br/ccivil_03/_ Ato2011-2014/2014/Lei/L12990.htm.

Lopes, A. (1995). Escola, socialização e cidadania: um estudo da criança negra numa escola pública de São Carlos. São Carlos: Editora da UFSCar.

Mello, J. C. R. S. (2011). Áreas de formação e diferenciação institucional: evidências de estratificação dos estudantes no ensino superior brasileiro. (Tese de Doutorado), Pontifícia Universidade Católica do Rio de Janeiro, Rio de Janeiro. 
Mello, L., \& Resende, U. P. (2019, janeiro-abril). Concursos públicos para docentes de universidades federais na perspectiva da Lei 12.990/2014: desafios à reserva de vagas para candidatas/os negras/os. Sociedade e Estado, 34(1), 61-184. Recuperado a partir de https://doi.org/10.1590/s0102-6992201934010007.

Müller, T. M. P., \& Coelho, W. N. B. C. (2013, outubro). A Lei no 10.639/03 e a formação de professores: trajetória e perspectiva. Revista da ABPN, 5(11), 2954. Recuperado a partir de https://abpnrevista.org.br/index.php/site/article/ view/188

Munanga, K. (Org.). (2005). Superando o racismo na escola. Brasília: Ministério da Educação, Secretaria de Educação Continuada, Alfabetização e Diversidade.

Pace, A. F. (2012). Afro-brasileiros e racismo institucional: o papel dos concursos na democratização de acesso aos cargos públicos. (Dissertação de Mestrado). Universidade Federal do Rio de Janeiro, Rio de Janeiro.

Paixão, M., Rossetto, I., Montovanele, F., \& Carvano, L. M. (Orgs.). (2010). Relatório anual das desigualdades raciais no Brasil: 2009-2010. Rio de Janeiro: Garamond. Recuperado a partir de http://www.geledes.org.br/wp-content/ uploads/2014/05/Relat\%C3\%B3rio_2009-2010.pdf

Portaria Normativa no 4, de 6 de abril de 2018. (2018, 6 abril). Regulamenta o procedimento de heteroidentificação complementar à autodeclaração dos candidatos negros, para fins de preenchimento das vagas reservadas nos concursos públicos federais, nos termos da Lei no 12.990, de 9 de junho de 2014. Diário Oficial da União, Brasília. Recuperado a partir de http://www. trtsp.jus.br/geral/tribunal2/ORGAOS/Min_Div/MPOG_PortNorm_04_18. html

Reis, I. C. F. (2010, outubro). Breves reflexões acerca da historiografia sobre a família negra na sociedade escravista brasileira oitocentista. Revista da ABPN, 1(2), 113-132. Recuperado a partir de https://abpnrevista.org.br/index.php/ site/article/view/293

Rosemberg, F., Bazilli, C., \& Silva, P. V. B. (2003). Racismo em livros didáticos brasileiros e seu combate: uma revisão da literatura. Educação e Pesquisa, 29(1), 125-146. Recuperado a partir de https://dx.doi.org/10.1590/S151797022003000100010

Santos, S. (2011). A metamorfose de militantes negros em negros intelectuais. 
Mosaico, 3(5), 102-125. Recuperado a partir de http://dx.doi.org/10.12660/ rm.v3n5.2011.62800

Schucman, L., Costa, E., \& Cardoso, L. (2012, julho-outubro). Quando a identidade racial do pesquisador deve ser considerada paridade e assimetria racial. Revista $A B P N, 4(8), 15-29$. Recuperado a partir de https://abpnrevista. org.br/index.php/site/article/view/247

Silva, M. A. B. (2016). Discursos étnico-raciais proferidos por pesquisadores/ as negroslas na pós-graduação: acesso, permanência, apoios e barreiras. (Tese de Doutorado). Pontifícia Universidade Católica de São Paulo, São Paulo.

Silva, P. B. G., \& Silvério, V. R. (Org.). (2003). Educação e açôes afirmativas: entre a injustiça simbólica e a injustiça econômica. Brasília: Instituto Nacional de Estudos e Pesquisas Educacionais Anísio Teixeira. Recuperado a partir de http://etnicoracial.mec.gov.br/images/pdf/publicacoes/educacao_acoes_ afirmativas.pdf

Telles, E. (2003). Racismo à brasileira: uma nova perspectiva sociológica. Rio de Janeiro: Relume Dumará.

Thompson, J. B. (2011). Ideologia e cultura moderna: teoria social critica na era dos meios de comunicação de massa. Petrópolis: Vozes. 